\title{
"Recurrent multiple cerebral infarctions related to the progression of adenomyosis: a case report"
}

\author{
Yasuhiro Aso* (D), Ryo Chikazawa, Yuki Kimura, Noriyuki Kimura and Etsuro Matsubara
}

\begin{abstract}
Background: Benign gynecologic tumor, such as uterine adenomyosis, has been suggested to develop hypercoagulability. Although some cases of cerebral infarction associated with adenomyosis have been reported, the mechanism of hypercoagulation initiated by adenomyosis is still not clear, and the therapeutic strategy is uncertain.

Case presentation: A 44-year-old woman was presented to our department with headache, left hand weakness, and gait disturbance during her menstrual phase. She had a history of adenomyosis and infertility treatment for 18 years and heavy menstrual bleeding. Magnetic resonance imaging on admission showed multiple hyperintense lesions in cortical and subcortical areas in the cerebrum and cerebellum on diffusion-weighted imaging. Transesophageal echocardiography showed neither embolic sources nor existence of foramen ovale. Her laboratory data revealed anemia, a high D-dimer level, and elevated levels of a mucinous tumor marker. She had adenomyosis and no malignancy was detected. Anticoagulation therapy with intravenous heparin followed by rivaroxaban did not prevent recurrence of cerebral infarction. We discontinued rivaroxaban, and started warfarin therapy with pseudomenopause treatment, which prevented recurrence for 6 months. Five months after her last pseudomenopause treatment, multiple cerebral infarctions occurred. Total hysterectomy was performed, which prevented recurrence of the multiple cerebral infarctions for 2 years without anticoagulation therapy.

Conclusions: Our findings reveal for the first time that anticoagulation therapy, including novel oral anticoagulants, had no preventive effect against cerebral infarctions associated with adenomyosis in a middle-aged woman. Although pseudomenopause treatment temporarily prevented recurrence, resection of the adenomyosis might be the most effective therapy in these cases.
\end{abstract}

Keywords: Multiple cerebral infarctions, Adenomyosis, Hypercoagulagulability, Anticoagulation therapy

\section{Background}

Uterine adenomyosis is a benign gynecologic condition, defined as the presence of ectopic endometrial glands and stroma surrounded by hyperplastic smooth muscle within the myometrium. Approximately $20 \%$ of women attending a general gynecologic clinic were revealed to have adenomyosis [1]. Although common symptoms are menorrhagia, dysmenorrhea, and heavy menstrual bleeding, one-third of women are asymptomatic [2].

Some patients with adenomyosis develop multiple cerebral infarctions (CIs) [3-5] (Table 1). Almost all patients

\footnotetext{
* Correspondence: yasuhiroaso@oita-u.ac.jp

Department of Neurology, Faculty of Medicine, Oita University, Yufu-city, Oita 879-5593, Japan
}

are middle-aged, with severe anemia and elevated serum carbohydrate antigen 125 (CA125). These patients are initially administered conventional anticoagulant therapy, which is often combined with gonadotropin-releasing hormone $(\mathrm{GnRH})$ therapy, and in some cases the adenomyosis is subsequently resected.

Here, we report the case of a middle-aged woman with adenomyosis who developed multiple CIs in her menstrual phase. Although she received edaravone and anticoagulation treatment with rivaroxaban, the recurrence of multiple CIs was not prevented. Pseudomenopause therapy with a GnRH agonist normalized her hypercoagulation state, but multiple CIs occurred after therapy was discontinued. Finally, a hysterectomy was performed, which successfully prevented CI recurrence. We propose that treatment of 
Table 1 Patient characteristics and therapy for $\mathrm{Cl}$ associated with adenomyosis

\begin{tabular}{|c|c|c|c|c|c|c|c|c|c|c|}
\hline \multirow[t]{2}{*}{ Case } & \multirow[t]{2}{*}{ Age (y.o.) } & \multirow{2}{*}{$\begin{array}{l}\text { D-dimer } \\
(\mu \mathrm{g} / \mathrm{ml})\end{array}$} & \multirow{2}{*}{$\begin{array}{l}\text { FDP } \\
(\mu \mathrm{g} / \mathrm{ml})\end{array}$} & \multirow{2}{*}{$\begin{array}{l}\text { CA125 } \\
(\mathrm{U} / \mathrm{ml})\end{array}$} & \multirow{2}{*}{$\begin{array}{l}\text { hemoglobin } \\
(\mathrm{g} / \mathrm{dl})\end{array}$} & \multicolumn{2}{|l|}{ treatment for $\mathrm{Cl}$} & \multirow{2}{*}{$\begin{array}{l}\text { treatment } \\
\text { for adenomyosis }\end{array}$} & \multirow{2}{*}{$\begin{array}{l}\text { recurrence } \\
\text { of } \mathrm{Cl}\end{array}$} & \multirow[t]{2}{*}{ reference } \\
\hline & & & & & & initial treatment & $\begin{array}{l}\text { subsequent } \\
\text { treatment }\end{array}$ & & & \\
\hline 1 & 45 & 1.1 & - & 159 & 8.4 & hepalin & $\begin{array}{l}\text { antipletelet } \\
\text { therapy }\end{array}$ & GnRH agonist & - & Yamashiro K et al. 2012 \\
\hline 2 & 44 & - & 5.9 & - & 7 & hepalin & warfalin & GnRH agonist & - & \\
\hline 3 & 50 & 0.57 & - & 42.6 & 6.9 & aspirin & - & GnRH agonist & - & \\
\hline 4 & 42 & 6.0 & - & 1750 & 8.6 & $\begin{array}{l}\text { antiplatelet } \\
\text { therapy }\end{array}$ & warfalin & GnRH agonist & + & \\
\hline 5 & 59 & 7.0 & - & 334.8 & - & $\begin{array}{l}\text { antithrombotic } \\
\text { therapy }\end{array}$ & - & - & - & Hijikata N et al. 2016 \\
\hline
\end{tabular}

CIs due to adenomyosis with anticoagulant therapy is not effective, and briefly discuss the underlying etiology and therapeutic strategy.

\section{Case presentation}

A 44-year-old woman experienced sudden onset of difficulty using her left hand and walking during her menstrual phase. She had a history of adenomyosis and infertility treatment for 18 years, and heavy menstrual bleeding. She complained of headache, abdominal pain, nausea, and had a fever $\left(37.7{ }^{\circ} \mathrm{C}\right)$ at presentation. She is not obese (BMI of $21.5 \mathrm{~kg} / \mathrm{m}^{2}$ ), had no history of taking steroids or contraceptives. Neurologic examination revealed left spatial neglect, left facial hypoalgesia, mild paresis in her left arm, and right pyramidal signs. Brain magnetic resonance imaging (MRI) revealed bilaterally multiple infarctions in the cerebrum and cerebellum, including cortical and subcortical lesions (Fig. 1a). MR angiography presented severe stenosis in the M2, M3, >and M4 portions of right middle cerebral artery (Fig. 1b). Contrast computed tomography revealed a splenic infarction (Fig. 1c). Blood examination revealed normocytic anemia (hemoglobin $10.3 \mathrm{~g} / \mathrm{dl}$, mean corpuscular volume $\left.90.5 \mathrm{\mu m}^{3}\right)$, thrombocytopenia $(112,000 / \mu \mathrm{l})$, and low-grade elevation of C-reactive protein $(2.9 \mathrm{mg} / \mathrm{dl})$. The serum levels of D-dimer $(17.0 \mu \mathrm{g} / \mathrm{ml}$, normal $<0.5 \mu \mathrm{g} / \mathrm{ml})$, CA125 $(2115 \mathrm{U} / \mathrm{ml}$, normal $<35.0 \mathrm{U} / \mathrm{ml})$, and carbohydrate antigen 19-9 (CA19-9) (1824 U/ml, normal < $37.0 \mathrm{U} / \mathrm{ml}$ ) were increased. Results of a hypercoagulable panel, including protein $C$ and S, antithrombin $\amalg$ level, lupus anticoagulant, and anticardiolipin antibody titers, were within normal limits. Pelvic MRI revealed giant adenomyosis (Fig. 1d), but no malignancy was detected. Fluorine-18-2-fluoro-2-deoxy-d-glucose (FDG) positron emission tomography revealed FDG accumulation in the adenomyosis, but no malignancy was detected by cervical cytology. The result of continuous electrocardiography monitoring, transesophageal echocardiography with

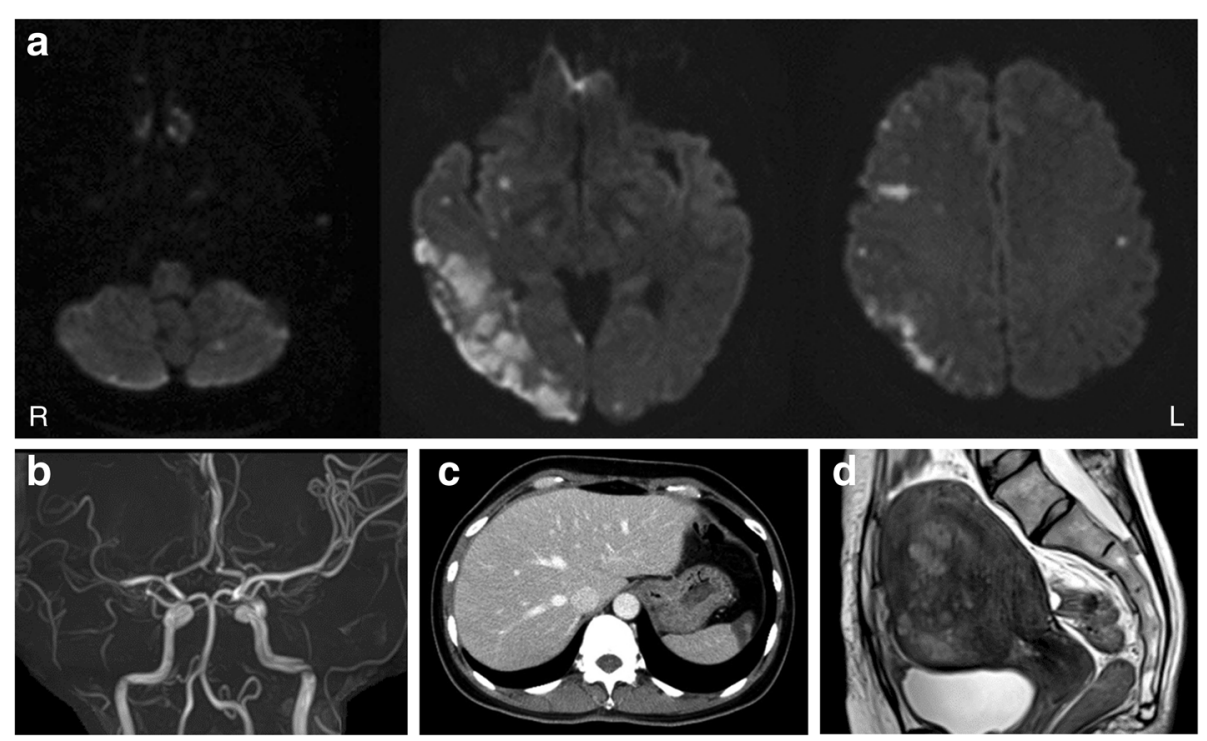

Fig. 1 Diffusion-weighted magnetic resonance imaging (MRI) scan of the brain reveals multiple infarctions in the cerebellum and cerebrum (a). The M2, M3, and M4 portions of the right middle cerebral artery were not well visualized by MR angiography (b). Contrast computed tomography revealed splenic infarction (c). Giant adenomyosis was revealed by a T2-weighted MRI scan of the pelvis (d) 
agitated saline injection, carotid ultrasonography, upper gastrointestinal endoscopy, and colonoscopy were normal.

She was treated with edaravone $(60 \mathrm{mg} /$ day $)$ and anticoagulated with heparin for 2 weeks. Subsequently, she was treated with rivaroxaban $(15 \mathrm{mg} /$ day). Her serum levels of D-dimer, CA125, and CA19-9 improved $(2.7 \mu \mathrm{g} / \mathrm{ml}, 911 \mathrm{U} / \mathrm{ml}$, and $501 \mathrm{U} / \mathrm{ml}$, respectively), and the treatment was continued.

At day 31, a day after her menstrual phase started, she complained of numbness in her left lower limb. Brain MRI revealed a new $\mathrm{CI}$ in the right cerebrum (Fig. 2a). The serum levels of D-dimer, CA125, CA19-9 were $2.4 \mu \mathrm{g} / \mathrm{ml}, 561 \mathrm{U} / \mathrm{ml}, 417 \mathrm{U} / \mathrm{ml}$, respectively. We discontinued the rivaroxaban treatment, and started anticoagulant therapy with warfarin. Afterwards, her menstrual bleeding increased, the anemia progressed, and the serum level of D-dimer increased $(14.1 \mu \mathrm{g} / \mathrm{ml})$. She started to receive pseudomenopause treatment with a $\mathrm{GnRH}$ agonist for the adenomyosis. Ten days after initiating the GnRH agonist treatment, her serum D-dimer level improved $(2.30 \mu \mathrm{g} / \mathrm{ml})$. She continued the warfarin and $\mathrm{GnRH}$ agonist once a month for 6 months, and showed no recurrence of CIs during that time. The serum levels of CA125, CA19-9 improved after 3 months of initiating the therapy (117 U/ml, $224 \mathrm{U} / \mathrm{ml}$, respectively).

She presented with transient weakness of her right lower limb and visited our clinic 5 months after her last GnRH agonist therapy, when her irregular menstrual bleeding had continued for a month. Brain MRI revealed new multiple cortical and subcortical infarctions in the left occipital lobe and right parietal lobe (Fig. 2b). Her serum D-dimer, FDP, CA125, and CA19-9 levels were elevated $(22.0 \mu \mathrm{g} / \mathrm{ml}, 56.5 \mu \mathrm{g} / \mathrm{ml}, 1291.6 \mathrm{U} / \mathrm{ml}$, and 803.2 $\mathrm{U} / \mathrm{ml}$, respectively). Anticoagulant therapy with warfarin was well controlled (PT-INR 2.5), and her electrocardiographic findings were normal. We concluded that total hysterectomy would be the most effective therapy for preventing CI recurrence. She underwent total hysterectomy and bilateral salpingo-oophorectomy, which was effective in not only preventing CI recurrence, but also for normalizing the serum D-dimer, FDP, CA125, and CA19-9 levels for the last 2 years.

\section{Discussion and conclusions}

Here we report a 44-year-old woman who developed multiple CIs after her menstrual phase, when the serum D-dimer, CA125, and CA19-9 levels were markedly elevated. Neither warfarin nor novel oral anticoagulants (NOAC) prevented CI recurrence. Although GnRH agonist therapy improved the levels of the three markers and prevented CI recurrence, the CIs recurred after the therapy was discontinued. Hysterectomy finally normalized the serum levels of the markers, and prevented CI recurrence. To our knowledge, this is the first report of an attempt to use NOAC to prevent recurrence of $\mathrm{CI}$ associated with adenomyosis. The clinical course of this case suggests that anticoagulation therapy is not sufficient to prevent blood hypercoagulation associated with adenomyosis, and thus resection may be the most effective therapy to normalize hypercoagulation and prevent the recurrence of thrombotic events.

Although reports of $\mathrm{CI}$ associated with adenomyosis are rare, some similar cases were reported. Yamashiro et al. [3] reported four cases of CI associated with adenomyosis in middle-aged women. Two of the women developed CIs in their menstrual phase. All of them presented with severe anemia (hemoglobin levels $6.9-8.6 \mathrm{~g} / \mathrm{dl}$ ). The D-dimer levels were elevated in two cases $(1.1 \mu \mathrm{g} / \mathrm{ml}$ and $6.0 \mu \mathrm{g} / \mathrm{ml}$ ), and CA125 was elevated in three cases (159 U/ml, $42.6 \mathrm{U} / \mathrm{ml}$, and $1750 \mathrm{U} / \mathrm{ml})$. All four cases were treated with antiplatelet medicine or an anticoagulant with a $\mathrm{GnRH}$ agonist. One case experienced recurrent multiple Cls after discontinuation of the therapy, when the levels of D-dimer and CA125 again increased $(4.1 \mu \mathrm{g} /$ $\mathrm{ml}$ and $907 \mathrm{U} / \mathrm{ml}$, respectively). Subsequently, she was treated with anticoagulant therapy and a GnRH agonist, and the D-dimer and CA125 levels normalized. These authors suggested that hypercoagulability in association with an elevated CA125 level, menstruation-related coagulopathy, or increased tissue factor (TF) expression level is a potential risk factor for developing CI. Hijikata et al. [5] reported 59-year-old woman with a 10-year history of hormone replacement therapy for menopausal symptoms who developed multiple CIs. Her laboratory tests revealed elevated CA125 $(334.8 \mathrm{U} / \mathrm{ml})$ and D-dimer $(7.0 \mu \mathrm{g} / \mathrm{ml})$
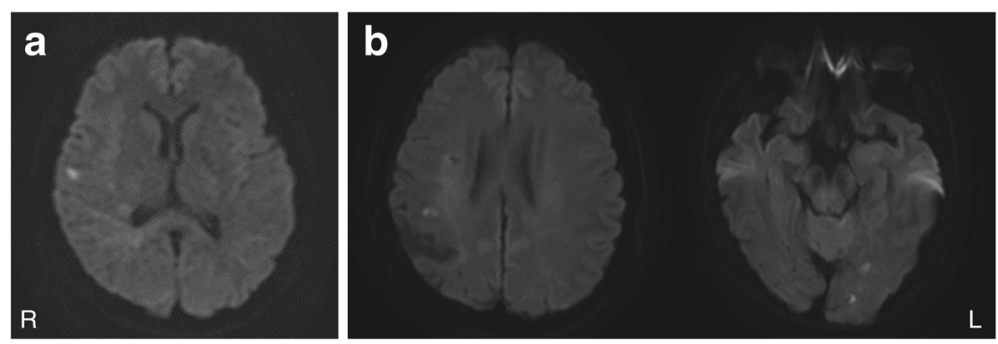

Fig. 2 Diffusion-weighted MRI revealed Cls in the right cerebrum (a). Multiple cortical and subcortical Cls in the left occipital lobe and right parietal lobe (b) 
levels. Anticoagulant therapy with unfractionated heparin was started and the hormone therapy was discontinued. Although antithrombotic therapy was discontinued on day 7 because of withdrawal bleeding, the $\mathrm{D}$-dimer and CA125 levels normalized. The authors concluded that both elevated CA125 levels and hormone replacement therapy are risk factors for hypercoagulability [5].

The mechanism of hypercoagulation initiated by adenomyosis remains uncertain. Several clinical studies reported an association of elevated serum CA125 and CA19-9 levels, and hypercoagulability [3-9]. CA125 is a typical mucin molecule [10], widely utilized for the diagnosis of epithelial ovarian cancer [11]. CA19-9 is a mucin-like high-molecular-weight glycoprotein utilized for the diagnosis of malignancies of the stomach, colon, and pancreas [12], and was recently reported to be associated with thrombosis in pancreatic adenocarcinoma [9]. These cancer-related-mucin molecules are suggested to play an important role in the hypercoagulative state in Trousseau's syndrome [13]. In our case, the levels of CA125 and CA19-9 were considerably high. We suppose that the high levels of these markers induced the recurrence of multiple cerebral infarctions in our case. A recent experimental study revealed that carcinoma mucin promotes thrombosis through adhesion-dependent, bidirectional signaling in neutrophils and platelets [14]. This mechanism may explain why the hypercoagulation in our case was not prevented by warfarin or NOAC.

In Trousseau's syndrome, induction of $\mathrm{TF}$ and its activity is postulated to promote hypercoagulability in patients with cancer $[15,16]$. Expression of TF is also significantly higher in adenomyotic lesions [17], and it renders microparticles procoagulant. Increased release of TF-exposing microparticles is suggested to contribute to the development of thrombotic complications [18]. This pathology might play an important role in multiple thromboses induced by adenomyosis.

Anemia is also a suspected cardiovascular factor [19, 20]. Anemia is considered a hyperkinetic state, and it disturbs endothelial adhesion molecule genes, which may lead to thrombus formation. In addition, anemia causes blood flow augmentation and turbulence, which may result in the migration of a thrombus, thus producing artery-to-artery embolism.

In conclusion, our findings suggest that middle-aged women with adenomyosis are at high risk for $\mathrm{CI}$ when the serum D-dimer, CA125, and CA19-9 levels are elevated. In those patients, anticoagulant therapy including NOAC therapy could not prevent $\mathrm{CI}$. Adenomyosis resection may be the most effective therapy for preventing $\mathrm{CI}$ in these cases.

\section{Abbreviations}

CA125: carbohydrate antigen 125; CA19-9: carbohydrate antigen 19-9; Cl: cerebral infarction; FDG: Fluorine-18-2-fluoro-2-deoxy-d-glucose;
GnRH: gonadotropin-releasing hormone; MRl: magnetic resonance imaging; NOAC: novel oral anticoagulants; TF: tissue factor

\section{Acknowledgments}

The authors would like to acknowledge the following: Prof. Teruyuki Hirano at Kyorin University School of Medicine, Japan. The staff of Obstetrics and Gynecology, Oita University Faculty of Medicine, Japan.

Availability of data and materials

All data related to this case report are contained within the manuscript.

\section{Authors' contributions}

$Y A, R C$ and $Y K$ examined and managed the patient; $Y A$ drafted the manuscript and created the figs; NK helped and revised the manuscript; EM revised the final approval of the version to be published. All authors read and approved the final manuscript.

\section{Ethics approval and consent to participate}

Not applicable.

\section{Consent for publication}

Written informed consent was obtained from the patient for publication of this case report.

\section{Competing interests}

The authors declare that they have no competing interests.

\section{Publisher's Note}

Springer Nature remains neutral with regard to jurisdictional claims in published maps and institutional affiliations.

Received: 31 August 2017 Accepted: 6 August 2018

Published online: 21 August 2018

\section{References}

1. Naftalin J, Hoo W, Pateman K, et al. How common is adenomyosis? A prospective study of prevalence using transvaginal ultrasound in a gynaecology clinic. Hum Reprod. 2012;27:3432-9.

2. Azziz R. Adenomyosis: current perspectives. Obstet Gynecol Clin N Am. 1989;16:221-35.

3. Yamashiro K, Tanaka R, Nishioka K, et al. Cerebral infarcts associated with adenomyosis among middle-aged women. J Stroke Cerebrovasc Dis. 2005; 21:910.

4. Yamashiro K, Furuya T, Noda K, et al. Cerebral infarction developing in a patient without cancer with a markedly elevated level of mucinous tumor marker. J Stroke Cerebrovasc Dis. 2012;21:619. e1-e2

5. Hijikata N, Sakamoto Y, Nito C, et al. Multiple cerebral infarctions in a patient with adenomyosis on hormone replacement therapy: a case report. J Stroke Cerebrovasc Dis. 2016;25:e183-4.

6. Nishioka K, Tanaka R, Tsutsumi S, et al. Cerebral dural sinus thrombosis associated with adenomyosis: a case report. J Stroke Cerebrovasc Dis. 2014; 23:1985-7.

7. Jovin TG, Boosupalli V, Zivkovic SA, et al. High titers of CA-125 may be associated with recurrent ischemic strokes in patients with cancer. Neurology. 2005;64:1944-5.

8. Tas F, Killic L, Bilgin E, et al. Clinical and prognostic significance of coagulation assays in advanced epithelial ovarian cancer. Int J Gynecol Cancer. 2013;23:276-81.

9. Woei-A-Jin FJ, Tesselaar ME, Garcia Rodriguez P, et al. Tissue factor-bearing microparticles and CA19.9: two players in pancreatic cancer-associated thrombosis? Br J Cancer. 2016;115:332-8.

10. Bast RC Jr, Feeney M, Lazarus $\mathrm{H}$, et al. Reactivity of a monoclonal antibody with human ovarian carcinoma. J Clin Invest. 1981;68:1331-7.

11. Maggino T, Gadducci A. Serum markers as prognostic factors in epithelial ovarian cancer: an overview. Eur J Gynaecol Oncol. 2000;21:64-9.

12. Lan MS, Bast RC Jr, Colnaghi Ml, et al. Co-expression of human cancerassociated epitopes on mucin molecules. Int J Cancer. 1987;39:68-72.

13. Varki A. Trousseau's syndrome: multiple definitions and multiple mechanisms. Blood. 2007;110:1723-9. 
14. Shao B, Wahrenbrock MG, Yao L, et al. Carcinoma mucins trigger reciprocal activation of platelets and neutrophils in a murine model of trousseau syndrome. Blood. 2011;118:4015-23.

15. Rickles FR. Mechanisms of cancer-induced thrombosis in cancer. Pathophysiol Haemost Thromb. 2006;35:103-10.

16. Rak J, Milsom C, May L, Klement P, et al. Tissue factor in cancer and angiogenesis: the molecular link between genetic tumor progression, tumor neovascularization, and cancer coagulopathy. Semin Thromb Hemost. 2006;32:54-70.

17. Li B, Chen M, Liu X, et al. Constitutive and tumor necrosis factor-a-induced activation of nuclear factor-KB in adenomyosis and its inhibition by andrographolide. Fertil Steril. 2013;100:568-77.

18. Van Es N, Bleker S, Sturk A, et al. Clinical significance of tissue factorexposing microparticles in arterial and venous thrombosis. Semin Thromb Hemost. 2015;41:718-27.

19. Kaiafa G, Savopoulos C, Kanellos I, et al. Anemia and stroke: where do we stand? Acta Neurol Scand. 2017;135:596-602.

20. Kannel WB, Gordon T, Wolf PA, et al. Hemoglobin and the risk of cerebral infarction: the Framingham study. Stroke. 1972;3(4):409-20.

Ready to submit your research? Choose BMC and benefit from:

- fast, convenient online submission

- thorough peer review by experienced researchers in your field

- rapid publication on acceptance

- support for research data, including large and complex data types

- gold Open Access which fosters wider collaboration and increased citations

- maximum visibility for your research: over $100 \mathrm{M}$ website views per year

At $\mathrm{BMC}$, research is always in progress.

Learn more biomedcentral.com/submissions 